\title{
Reliability and Feasibility of the Four Square Step Test for Use in Children with Cerebral Palsy: A Pilot Study
}

\author{
Edward James R. Gorgon \\ University of the Philippines \\ Gilbert O. Madriaga \\ University of the Philippines \\ Minerva Z. Gomez-Cailao \\ NMS Healthcare of Annapolis, Annapolis, Maryland \\ Levin S. Abdon \\ Quality Life Discoveries, Inc, Quezon City \\ Mary Ann D. Boniquit \\ Thera Needs, Manila
}

Follow this and additional works at: https://nsuworks.nova.edu/ijahsp

Part of the Medicine and Health Sciences Commons

\section{Recommended Citation}

Gorgon ER, Madriaga GO, Gomez-Cailao MZ, Abdon LS, Boniquit MA. Reliability and Feasibility of the Four Square Step Test for Use in Children with Cerebral Palsy: A Pilot Study. The Internet Journal of Allied Health Sciences and Practice. 2014 Apr 01;12(2), Article 5.

This Manuscript is brought to you for free and open access by the College of Health Care Sciences at NSUWorks. It has been accepted for inclusion in Internet Journal of Allied Health Sciences and Practice by an authorized editor of NSUWorks. For more information, please contact nsuworks@nova.edu. 


\title{
Reliability and Feasibility of the Four Square Step Test for Use in Children with Cerebral Palsy: A Pilot Study
}

\begin{abstract}
Purpose: The ability to maintain standing balance with a moving base of support and while making rapid postural adjustments is important for independence in various functional activities. Clinical tests and measures have not addressed this ability in children with disability. This pilot study examined the feasibility and reliability of the Four Square Step Test (FSST) as a test of dynamic balance in children with cerebral palsy (CP). Method: Four children with CP (Gross Motor Function Classification Scale levels I-II) were tested on the FSST by 3 assessors on the first occasion (interrater reliability) and repeat-tested by 1 assessor after 2 weeks (test-retest reliability). Six children with typical development (TD) were tested on a separate occasion to explore any between-group difference in performance. Results: The FSST was easy to setup, required no specialized equipment, could be completed in 5 minutes, and might be carried out by clinicians with limited experience in pediatric therapy. It demonstrated excellent interrater reliability (ICC = $0.832)$ and test-retest reliability (ICC $=0.979)$ in children with CP. Compared with FSST times for children with TD (mean $=9.12 \pm 2.67$ seconds), times for children with CP (mean $=18.38 \pm 9.02$ seconds) were significantly slower $(p=0.019$, Mann-Whitney $U=-2.345)$. Conclusions and Recommendations: The pilot study provides initial evidence on the potential usefulness of the FSST as a test of dynamic standing balance in children with CP. This warrants further investigation of the clinimetric properties of the FSST using an adequate sample size.
\end{abstract}

\section{Author Bio(s)}

- Edward James R Gorgon, Department of Physical Therapy, College of Allied Medical Professions, University of the Philippines Manila.

- Gilbert O. Madriaga, Department of Epidemiology and Biostatistics, College of Public Health, University of the Philippines Manila.

- Minerva Z. Gomez-Cailao, NMS Healthcare of Annapolis, Bay Ridge Healthcare Center, Annapolis, Maryland.

- Levin S. Abdon, Quality Life Discoveries, Inc., Quezon City.

- Mary Ann D. Boniquit, Thera Needs, Manila. 


\title{
IJAHSP \\ The Internet Joư⿱n⿵⿰丿亅口阝 \\ Dedicated to allied health professional practice and education \\ http://ijahsp.nova.edu Vol. 12 No. 2 ISSN 1540-580X
}

\section{Reliability and Feasibility of the Four Square Step Test for Use in Children with Cerebral Palsy: A Pilot Study}

\author{
Edward James R. Gorgon, MPhysio, PTRP1 \\ Gilbert O. Madriaga PTRP2 \\ Minerva Zaniebeth Gomez-Cailao RPT, PTRP3 \\ Levin S. Abdon, PTRP4 \\ Mary Ann D. Boniquit, PTRP5
}

1. Department of Physical Therapy, College of Allied Medical Professions, University of the Philippines Manila. ${ }^{a}$

2. Department of Epidemiology and Biostatistics, College of Public Health, University of the Philippines Manila. a

3. NMS Healthcare of Annapolis, Bay Ridge Healthcare Center, Annapolis, Maryland. ${ }^{b}$

4. Quality Life Discoveries, Inc., Quezon City. ${ }^{a}$

5. Thera Needs, Manila. ${ }^{a}$

\author{
a. Philippines \\ b. United States
}

\begin{abstract}
Purpose: The ability to maintain standing balance with a moving base of support and while making rapid postural adjustments is important for independence in various functional activities. Clinical tests and measures have not addressed this ability in children with disability. This pilot study examined the feasibility and reliability of the Four Square Step Test (FSST) as a test of dynamic balance in children with cerebral palsy (CP). Method: Four children with CP (Gross Motor Function Classification Scale levels III) were tested on the FSST by 3 assessors on the first occasion (interrater reliability) and repeat-tested by 1 assessor after 2 weeks (test-retest reliability). Six children with typical development (TD) were tested on a separate occasion to explore any between-group difference in performance. Results: The FSST was easy to setup, required no specialized equipment, could be completed in 5 minutes, and might be carried out by clinicians with limited experience in pediatric therapy. It demonstrated excellent interrater reliability $(I C C=0.832)$ and test-retest reliability $(I C C=0.979)$ in children with CP. Compared with FSST times for children with TD (mean $=9.12 \pm 2.67$ seconds), times for children with CP (mean $=18.38 \pm 9.02$ seconds) were significantly slower $(p=0.019$, Mann-Whitney $U=-2.345)$. Conclusions and Recommendations: The pilot study provides initial evidence on the potential usefulness of the FSST as a test of dynamic standing balance in children with CP. This warrants further investigation of the clinimetric properties of the FSST using an adequate sample size.
\end{abstract}

\section{INTRODUCTION}

Problems in standing balance, whether in steady stance or when rapidly shifting weight, have been documented in children with cerebral palsy (CP). 1,2 Impairments such as postural deviations, greater co-activation of agonist and antagonist muscles during walking, delayed and disorganized timing of muscle recruitment, tone abnormalities, and difficulty increasing the amplitude of muscle response to increasing threats to balance contribute to impaired balance in children with $\mathrm{CP} .{ }^{3}$ Poor balance causes difficulties in children's functional activities because good balance (i.e. the ability to anticipate, avoid and recover from either internally-generated or externally-generated instability) is integral to gross motor development.4-5

Balance is affected by the task as well as the environment in which the task is performed; thus, balance assessment should consider task and environment requirements. ${ }^{6}$ For example, tasks performed over a small or with a moving base of support (BOS) pose greater demands on balance than those done on a larger or non-moving BOS. Environmental constraints, such as the presence of physical obstacles and time constraints, likewise shape the patterns of stepping and eye-head movement used

(C) The Internet Journal of Allied Health Sciences and Practice, 2014 
to maintain stability in standing. Although several clinical tests of standing balance have been validated for children with $\mathrm{CP}$, most involve testing on a stationary base of support and are limited in assessing balance in conditions with task and environmental constraints. ${ }^{7}$ No test has examined important balance maneuvers for daily life like stepping backward and sideway and over obstacles, and making rapid changes in direction in this population.

The Four Square Step Test (FSST) measures rapid stepping in different directions and over low obstacles. ${ }^{8}$ It is highly practical to administer, with little time, equipment and space requirements. FSST measurements have been shown to be reliable and valid in non-disabled and disabled adult groups. ${ }^{8-13}$ Also, scores on the FSST have discriminated between non-disabled groups and people with stroke. ${ }^{10}$ Measurement properties, however, are population-specific and thus need to be established for other client groups ${ }^{14}$ This pilot study explored the feasibility and interrater and test-retest reliability of the FSST on children with CP. Test performance of children with $\mathrm{CP}$ was also compared with controls.

\section{METHOD}

The pilot study was approved by the ethics review committee of the University of the Philippines Manila - College of Allied Medical Professions.

\section{Participants}

Ten children (4 with CP and 6 controls) participated. The children's parents provided written consent while the children gave verbal assent to commence participation in the study. Inclusion criteria for the children with $\mathrm{CP}$ were age between 7 to 12 years, medical diagnosis of CP, Gross Motor Function Classification System (GMFCS) levels I-III, and ability to understand at least 2step commands. ${ }^{15}$ Patients were conveniently sampled from an outpatient pediatric clinic in the Philippines. Excluded were children with severe visual, vestibular or cognitive impairment, or behavioral problems. Controls were typically-developing children who were within the age range of 7 to 12 years.

\section{Test Protocol}

Testing sessions were two weeks apart for children with CP. On the first session, 3 trained assessors ( 1 physical therapist with 2 years of pediatric therapy experience and 2 final-year physical therapy students) administered the FSST independently for interrater reliability. After two weeks, the participants were tested again by the physical therapist for test-retest reliability. Scores from the first session were made unavailable to the assessor on the second session to minimize bias. Children with typical development (TD) were tested on a separate day. Testing conditions, including set up, instructions, and time of the day, were kept similar across all testing sessions. The participants wore comfortable clothing and usual footwear.

The FSST was administered according to the original protocol (see Figure 1). ${ }^{8}$ Four standard canes configured as a cross on the floor created 4 squares. Initially standing in square 1 and facing square 2 , participants stepped into each square in the sequence $2,3,4,1,4,3,2,1$. The test required stepping forward, backward and sideward. Participants completed the step sequence as fast as possible without touching the canes and with both feet making contact with each square. A digital stopwatch was used to quantify completion time. Time started when one foot contacted the floor on square 2 and ended when the last foot touched the floor on square 1. In this study, colored paper markers were placed on the corners of the squares to cue the step sequence. If the child showed difficulty following the number sequence, the colors of the markers were used to instruct the sequence: yellowgreen-blue-black-blue-green-yellow-black. The testing surface comprised non-skid rubber mats and was set up away from obstructions.

Each assessor provided a test demonstration and 1 practice trial for each participant. Instructions were given in either English or Filipino, depending on the language used by the child. The participants faced forward in the same direction during testing. If the child could not follow the instructions, cues such as pointing to the appropriate square or tapping the shoulder, hip or thigh were provided. When a participant performed the test sequence incorrectly, lost balance, or touched a cane with a foot, the trial was stopped and repeated. Participants rested between trials to avoid fatigue. The best time of 2 successful trials was utilized. The number of attempts required by each participant before successful completion was recorded. 


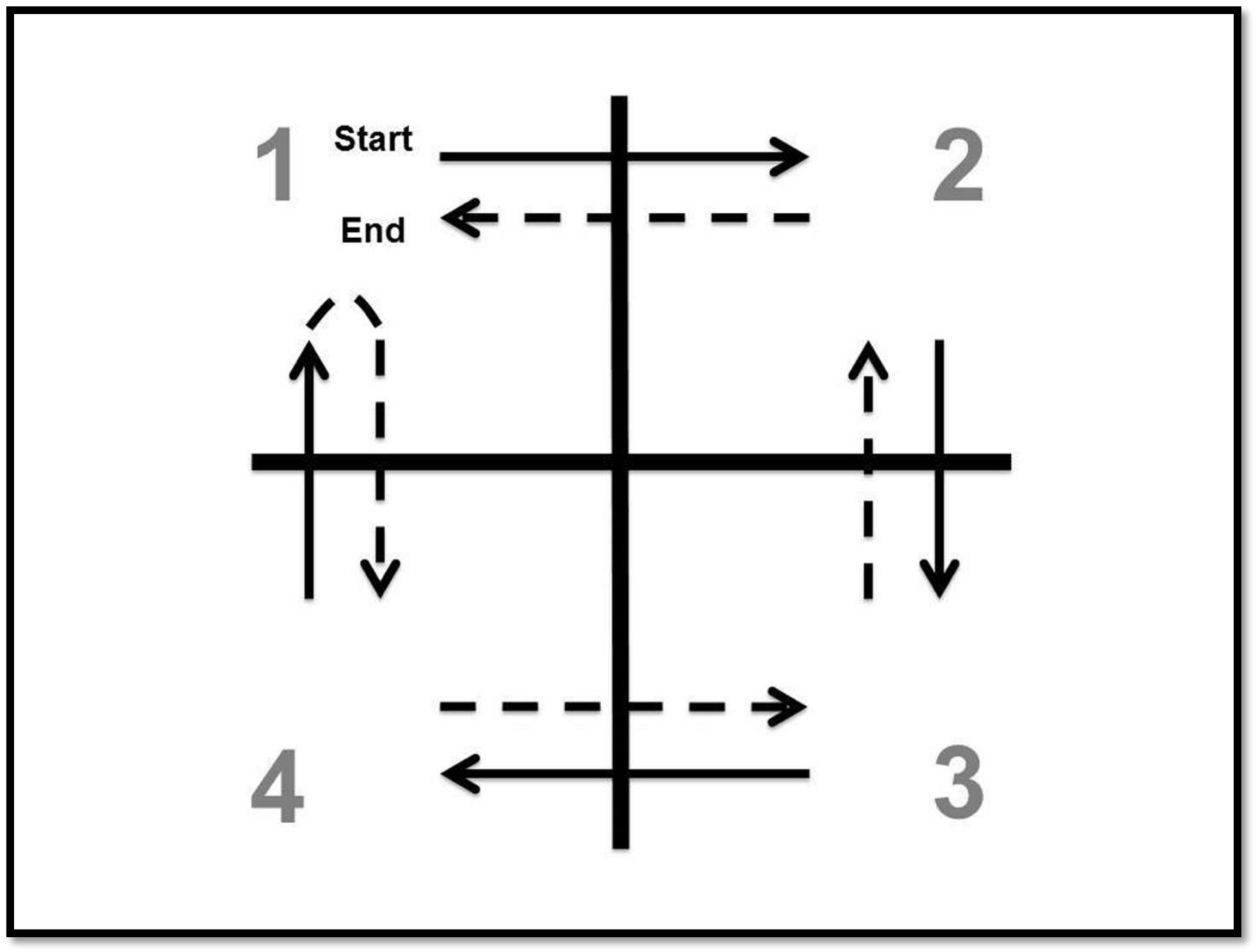

Figure 1 FSST set up and stepping sequence

\section{Data Analysis}

Intraclass correlation coefficients (ICC) were calculated for interrater and test-retest reliability. Reliability was excellent if the ICC was $\geq 0.80$; adequate if it ranged 0.60 to 0.79 ; and poor if it was $<0.60 .{ }^{16}$ Potential between-group difference in test performance was examined using the Mann Whitney $U$ test. The alpha level was set at .05.

\section{RESULTS}

Participant characteristics are summarized in Table 1. Two had CP of the diplegic type, 1 of the athetoid type and 1 of the spastic (quadriplegia) type. None was dependent on an assistive mobility device (GMFCS levels I [Walks indoors and outdoors, and climb stairs without limitations. Performs gross motor skills including running and jumping but speed, balance, and coordination are reduced.] and II [Walks indoors and outdoors, and climb stairs holding onto a railing but experiences limitations walking on uneven surfaces and inclines, and walking in crowds or confined spaces. Have at best only minimal ability to perform gross motor skills such as running and jumping.]). ${ }^{15}$ All were undergoing physical therapy, occupational therapy, speech therapy, or a combination of therapies. 
Table 1. Group characteristics of children with $\mathrm{CP}$ and TD

\begin{tabular}{lll}
\hline & Children with CP $(\mathrm{n}=4)$ & Children with TD $(\mathrm{n}=6)$ \\
\hline Age $(\mathrm{yr})$ & $9 \pm 2$ & $9 \pm 2$ \\
Height $(\mathrm{cm})$ & $121 \pm 6$ & $131 \pm 17$ \\
Weight $(\mathrm{kg})$ & $23 \pm 7$ & $26 \pm 10$ \\
Gender (male/female) & $1 / 3$ & $3 / 3$ \\
$\begin{array}{l}\text { GMFCS level } \\
\quad \text { Level I }\end{array}$ & \\
$\quad 3$ & $\mathrm{NA}$ \\
$\quad$ Level II & 1 & $\mathrm{NA}$ \\
\hline CP = cerebral palsy, TD = typical development, GMFCS = Gross Motor Function Classification System, NA = not applicable
\end{tabular}

FSST mean scores and reliability estimates are reported in Table 2. Children with CP required longer test completion times on both test occasions compared with children with TD $(p=0.019$, Mann-Whitney $U=-2.345)$, by 9.26 s on session 1 and $9.57 \mathrm{~s}$ on session 2. The 3 participants with GMFCS level I performed worse than children with TD by $6.14 \mathrm{~s}$ but better than the participant with GMFCS level II by 13.65s. Testing times recorded independently by the assessors showed excellent interrater reliability (ICC $=.832 ; 95 \%$ confidence interval, .395 to .987$)$. Repeated measurement by 1 assessor demonstrated excellent test-retest reliability (ICC $=.979 ; 95 \%$ confidence interval, .805 to .999$)$.

Table 2. Interrater and test-retest reliability (ICC, $p)$ in children with CP and mean scores for children with CP and TD

\begin{tabular}{lll}
\hline & Children with CP $(n=4)$ & Children with TD $(n=6)$ \\
\hline Mean scores (s) & & \\
Session 1 & $18.38 \pm 9.02$ & $9.12 \pm 2.67$ \\
Session 2 & $18.69 \pm 7.13$ & \\
Interrater reliability & $.832, .003$ & \\
Test-retest reliability & $.979,<.001$ & \\
\hline
\end{tabular}

$\mathrm{CP}=$ cerebral palsy, $\mathrm{TD}=$ typical development

\section{DISCUSSION}

This study provides initial evidence for the potential of the FSST as a feasible and reliable tool for assessing dynamic balance in children with CP. The test was set up and administered in 5 to 10 minutes with little required equipment and space. Training of assessors comprised watching a videotaped test administration and several simulations led by the principal investigator in one session. Issues encountered by the children with $\mathrm{CP}$ included difficulty in facing in the same direction, observing the correct stepping sequence, clearing the canes, and placing both feet on the square before moving onto the next. Visual and tactile cues were helpful to the participants and close supervision by 1 assessor promoted safety. All participants required 2 to 3 attempts before successfully completing the test trials. This finding points to the need for more practice trials when using this test. Moreover, it highlights that the FSST requires specific minimum cognitive and physical abilities to be successfully completed. 8,10 In this study, cognitive ability of the participants was not formally assessed. Also, no children at GMFCS level III participated. Thus the feasibility of the FSST for specific cognitive levels and lower motor abilities needs to be explored.

Excellent interrater and test-retest reliability estimates were consistent with those reported for adult client groups.-13 Given the assessors' limited experience in clinical practice and using the test, these estimates support the potential utility of the FSST for use by "average" service providers. The excellent test-retest reliability estimate also suggests that the FSST may have potential for longitudinal outcomes assessment for children with CP. Differences in scores across participants with different motor abilities are consistent with the result of a recent study on adults with chronic stroke. ${ }^{10}$ This finding suggests the FSST's potential to discriminate among different balance abilities. The FSST may provide a means of identifying the need for further balance training in patients with mild disability or those who have become relatively functional but remain unable to participate in more balancechallenging activities in settings like the school or play in the outdoor environment. These findings however must be viewed with caution given the small sample sizes utilized for both the CP and TD groups in this pilot investigation.

\section{CONCLUSION}

Although clearly limited by its small sample size, this pilot study is the first to provide initial evidence for the potential reliability and feasibility of the FSST for use on children with CP. The FSST appears to be a highly practical clinical tool for measuring dynamic balance dimensions not covered yet by existing clinical tests and measures. The positive preliminary findings despite the sample size provide an impetus for further, adequately-powered research to clarify the reliability and feasibility of the FSST in this client population. 


\section{ACKNOWLEDGEMENT}

The authors wish to thank the children who participated in the study. Warm appreciation is likewise extended to Aila Nica Bandong, Angelo Abella, and Emily Joy Rodriguez for their respective contributions in the data collection process, and Lenin Grajo for his assistance in accessing some of the key literature used in the study.

\section{REFERENCES}

1. Nashner LM, Shumway-Cook A, Marin O. Stance posture control in select groups of children with cerebral palsy: deficits in sensory organization and muscular coordination. Exp Brain Res. 1983;49:393-409. [PMID 6641837]

2. Liao HF, Jeng SF, Lai JS, Cheng $\mathrm{CK}, \mathrm{Hu} \mathrm{MH}$. The relation between standing balance and walking function in children with spastic diplegic cerebral palsy. Dev Med Child Neurol. 1997;39:106-112. [PMID 9062425]

3. Woollacott MH, Shumway-Cook A. Postural dysfunction during standing and walking in children with cerebral palsy: What are the underlying problems and what new therapies might improve balance? Neural Plast. 2005;12:211-9. [PMID 16097489]

4. Gan SM, Tung LC, Tang YH, Wang CH. Psychometric properties of functional balance assessment in children with cerebral palsy. Neurorehabil Neural Repair. 2008;22:745-53. [PMID 18645187]

5. Liao HF, Hwang AW. Relations of balance function and gross motor ability for children with cerebral palsy. Percept Motor Skill. 2003;96:1173-84. [PMID 12929770]

6. Huxham F, Goldie P, Patla A. Theoretical considerations in balance assessment. Aust J Physiother. 2001;47:89-100. [PMID 11552864]

7. Saether R, Helbostad JL, Riphagen II, Vik T. Clinical tools to assess balance in children and adults with cerebral palsy: a systematic review. Dev Med Child Neurol. 2013;55:988-99. [PMID: 23679987]

8. Dite W, Temple V. A clinical test of stepping and change of direction to identify multiple falling older adults. Arch Phys Med Rehabil. 2002;83:1566-71. [PMID 12422327]

9. Whitney S, Marchetti G, Morris L, Sparto P. The reliability and validity of the Four Square Step Test for people with balance deficits secondary to a vestibular disorder. Arch Phys Med Rehabil. 2007;88:99-104. [PMID 17207683]

10. Goh EY, Chua SY, Hong SJ, Ng SS. Reliability and concurrent validity of Four Square Step Test scores in subjects with chronic stroke: a pilot study. Arch Phys Med Rehabil. 2013;94:1306-11. [PMID 23416218]

11. Blennerhassett JM, Jayalath VM. The Four Square Step Test is a feasible and valid clinical test of dynamic standing balance for use in ambulant people poststroke. Arch Phys Med Rehabil. 2008;89:2156-61. [PMID 18996245]

12. Wagner JM, Norris RA, Van Dillen LR, Thomas FP, Naismith RT. Four Square Step Test in ambulant persons with multiple sclerosis: validity, reliability, and responsiveness. Int J Rehabil Res. 2013 Sep;36(3):253-9. [PMID 23511117] doi: 10.1097/MRR.0b013e32835fd97f.

13. Duncan RP, Earhart GM. Four square step test performance in people with Parkinson disease. J Neurol Phys Ther. 2013;37:2-8. [PMID 23364168]

14. Portney LG, Watkins M. Foundations of clinical research: applications to practice. 3rd ed: Pearson Prentice Hall, New Jersey; 2009.

15. Palisano R, Rosenbaum $P$, Walter $S$. Development and reliability of a system to classify gross motor function in children with cerebral palsy. Dev Med Child Neurol. 1997;39:214-23. [PMID 9183258]

16. Law M. Outcome measures rating form. CanChild Centre for Disability Research, Ontario; 2004. Retrieved from http://www.canchild.ca/en/canchildresources/resources/measguid.pdf 